\title{
Amputasi ektremitas kaudalis sinistra pada kucing domestik akibat gigitan biawak
}

\author{
Syafruddin ${ }^{1}$, Intan Rahayu ${ }^{2}$, Budianto Panjaitan ${ }^{1}$ \\ ${ }^{1}$ Laboratorium Klinik, Fakultas Kedokteran Hewan, Universitas Syiah Kuala, Banda Aceh \\ ${ }^{2}$ Mahasiswa Koasistensi, Fakultas Kedokteran Hewan, Universitas Syiah Kuala, Banda Aceh
}

\begin{abstract}
ABSTRAK: Seekor kucing domestik jantan dengan nama Sarji, berwarna hitam-putih, berat badan 3,1 kg dan berumur $\pm 2,5$ tahun dibawa ke Laboratorium Klinik dengan keadaan luka akibat gigitan biawak. Kondisi os tibia ekstremitas sinistra distal menjulur keluar dari muskulus yang sudah tidak ditutupi kulit dan bagian metatarsal telah mengalami kematian jaringan. Kucing ditangani dengan tindakan amputasi ekstremitas kaudalis khususnya os tibia fibula sinistra. Pasien diberikan antibiotik, anti inflamasi dan anti nyeri pascaamputasi. Pasien tidak menjalani perawatan pascaoperasi secara intensif di klinik karena permintaan pemilik. Proses kesembuhan kucing pascaamputasi berjalan dengan baik berdasarkan informasi pemilik. Luka telah mengering dan hewan mampu berjalan dengan baik menggunakan ketiga kaki lainnya.
\end{abstract}

\section{Kata kunci:}

amputasi, kucing, ektremitas kaudalis sinistra, gigitan biawak

\section{- PENDAHULUAN}

Penanganan pada kasus fraktur meliputi 4 konsep dasar, antara lain: rekognisi, reposisi, retensi, dan rehabilitasi (Johnston \& Tobias 2017). Rekognisi harus dilakukan sedini mungkin untuk mengetahui lokasi dan tingkat keparahan fraktur serta untuk membantu menentukan jenis penanganan yang tepat. Dalam beberapa kasus apabila fiksasi internal dan eksternal tidak dapat dilakukan, maka dapat dilakukan penanganan dengan cara amputasi (Ningrat \& Pemayun, 2016). Indikasi dari amputasi adalah keadaan fraktur multiple, tulang patah menjadi potongan tulang yang lebih kecil sehingga tidak dapat dilakukan fiksasi internal maupun eksternal, nekrosis jaringan disekitar fraktur, adanya tumor pada tulang, deformitas organ serta adanya infeksi yang berat atau yang beresiko tinggi menyebar ke organ lainnya (Ningrat \& Pemayun, 2016).

Tulisan ini melaporkan kasus pada seekor kucing yang mengalami fraktur dengan luka terbuka pada bagian distal os tibia fibula sinistra akibat cabikan gigi biawak dan telah berlangsung selama 3 hari dengan jaringan yang mengalami nekrosis sehingga harus dilakukan amputasi.

\section{- KASUS}

Anamnesis: Kucing tidak pulang kerumah untuk makan selama 3 hari dan ditemukan di sekitar tepi sungai tidak jauh dari rumah dengan keadaan berdarah yang sangat parah akibat gigitan biawak. Kondisi pasien: Os tibia ekstremitas sinistra distal tampak menjulur keluar dari muskulus yang sudah tidak ditutupi kulit dan bagian metatarsal yang mengalami kematian jaringan syaraf dan sudah berlendir, jaringan muskulus dan tulang sudah mengalami nekrosis. Sinyalemen: Kucing domestik jantan dengan nama Sarji, berwarna hitam-putih, berat badan 3,1 kg dan berumur $\pm 2,5$ tahun. Kucing ini milik ibu Uni yang berasal dari Gampong Keudah, Banda Aceh. Diagnosa: Luka gigitan dan terjadi nekrosa pada bagian ektremitas kaudalis sinistra. Prognosa: Infausta. Terapi: Amputasi esktremitas kaudalis sinistra.

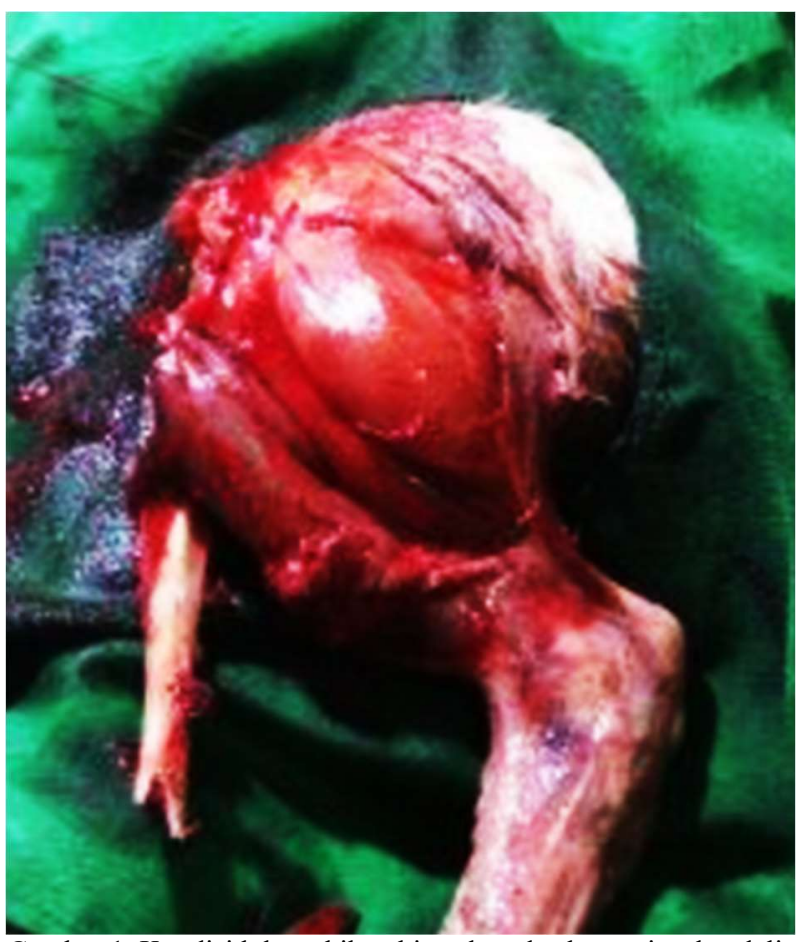

Gambar 1. Kondisi luka cabikan biawak pada ekstremitas kaudalis sisnistra kucing domestik.

Diterima: 30-05-2020 | Direvisi: 28-06-2020 | Disetujui: 03-07-2020

(C) 2020 CC-BY-SA. Ini adalah artikel Open Access yang didistribusikan berdasarkan ketentuan dari Creative Commons Attribution ShareAlike 4.0 International License (https://creativecommons.org/licenses/by-sa/4.0/). 


\section{- HASIL DAN PEMBAHASAN}

Tindakan amputasi ini dilakukan dengan terlebih dahulu melakukan anestesi menggunakan kombinasi ketamin dan xilazin. Kombinasi kedua obat ini mempunyai beberapa keuntungan yaitu ekonomis, mudah dalam pemberian, induksi yang cepat, mempunyai pengaruh relaksasi yang baik serta jarang menimbulkan komplikasi klinis (Dharmayudha et al. 2012). Hewan dibaringkan diatas meja operasi dengan posisi merebah kesamping kanan. Lokasi amputasi tidak dicukur karena keadaan luka terbuka yang parah (Gambar 1).

Penyayatan dilakukan pada bagian persendian antara os femur dan os tibia fibula. Arteri dan vena femoralis serta vena saphena diligasi terlebih dahulu untuk menghindari terjadinya perdarahan. Pemotongan tulang dilakukan dengan menggunakan gunting tulang atau tang sirurgis dan pisau bedah (Gambar 2A).

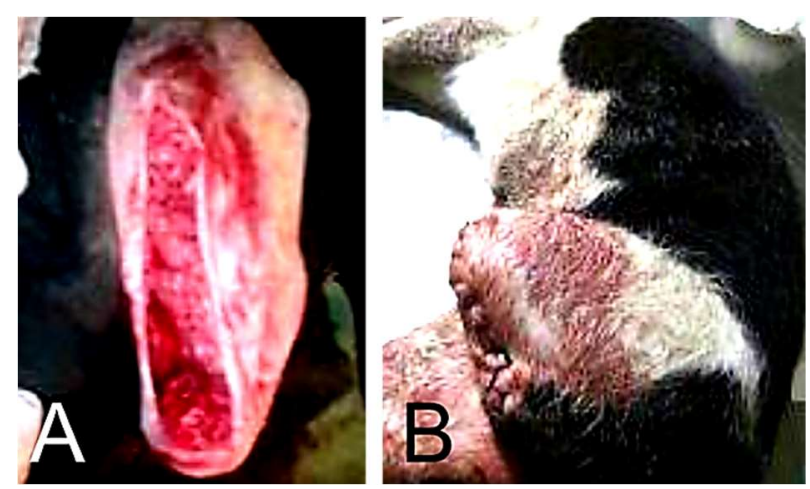

Gambar 2. Amputasi pada kucing. (A) Pascaamputasi tulang dan otot dan (B) pascapenjahitan jaringan otot dan kulit.

Tulang os tibia fibula selanjutnya dipisahkan dari os femur, kulit yang masih menutupi muskulus bagian femur dicukur dan dirapikan untuk menutup bagian yang telah diamputasi. Penjahitan muskulus dengan metode simple continous dan kulit dijahit dengan pola simple interrupted menggunakan benang vicryl ukuran $3 / 0$. Luka yang telah dijahit kemudian ditutup dengan metode jahitan simple interrupted dan dibersihkan menggunakan kasa steril yang dibasahi $\mathrm{NaCl}$ fisiologis, kemudian dioles dengan iodine tincture (Gambar 2B). Daerah jahitan pascaoperasi diberikan salep yang mengandung antibiotik kloramfenikol.
Pascaamputasi pasien diberikan antibiotik oral yang dengan tujuan pencegahan infeksi sekunder pascaoperasi (Swedish Veterinary Assosiation, 2009) serta analegsik dan anti-inflamasi (Johnston \& Tobias 2017). Pasien tidak menjalani perawatan intensif di klinik karena permintaan pemilik. Namun, dokter hewan menyarankan agar pasien kembali setelah 3 hari pascaoperasi dan obat oral yang diberikan telah habis diberikan pada kucing. Hal ini mengacu pada anjuran Swedish Veterinary Assosiation (2009) bahwa selama 3 hari pascaoperasi, penyembuhan luka dan penyatuan kulit daerah operasi memberikan perkembangan yang baik dengan tidak adanya penimbunan cairan didaerah operasi. Berdasarkan keterangan dari pemilik, luka telah mengering dan kucing mampu berjalan dengan baik menggunakan ketiga kaki lainnya.

\section{- SIMPULAN}

Penanganan kasus fraktur terbuka dan mengalami nekrosis jaringan muskulus dan tulang bagian distal os tibia sinistra pada kucing domestik akibat gigitan biawak yaitu dengan cara melakukan tindakan amputasi pada persendian lutut.

\section{- INFORMASI PENULIS}

Penulis untuk Korespondensi

*S: syafruddinkh@unsyiah.ac.id

Laboratorium Klinik, Fakultas Kedokteran Hewan, Universitas Syiah Kuala, Banda Aceh. Jl. T. Hasan Krueng Kalee No. 4, Banda Aceh. Indonesia.

\section{- PUSTAKA ACUAN}

Dharmayudha AAGO, Gorda IW, Warditha AAGJ. 2012. Perbandingan anastesi Xylaxin-Ketamin Hidroklorida dengan anastesi TiletaminZolazepam terhadap frekuensi denyut jantung dan pulsus anjing lokal. Buletin Veteriner Udayana. 4 (1): 9-15.

Johnston SA, Tobias KM. 2017. Veterinary Surgery: Small Animal Expert Consult-E-Book. Elsevier Health Sciences.

Ningrat DAWK, Pemayun IGAGP. 2016. Fraktur Os Tibia Fibula pada Anjing Lokal. Laporan Koasistensi Bedah. Laboratorium Bedah Veteriner. Fakultas Kedokteran Hewan. Universitas Udayana.

Swedis Veterinary Association. 2009. Guidelines for Clinical Use of Antibiotics in the Treatment of Dogs and Cats. Sweden. 